\title{
Genomic imprinting in marsupial placentation
}

\author{
Marilyn B Renfree, Eleanor I Ager, Geoff Shaw and Andrew J Pask \\ Department of Zoology, ARC Centre of Excellence for Kangaroo Genomics, The University of Melbourne, Melbourne, \\ Victoria 3010, Australia
}

Correspondence should be addressed to M B Renfree; Email: m.renfree@unimelb.edu.au

\begin{abstract}
Genomic imprinting is a widespread epigenetic phenomenon in eutherian mammals, which regulates many aspects of growth and development. Parental conflict over the degree of maternal nutrient transfer is the favoured hypothesis for the evolution of imprinting. Marsupials, like eutherian mammals, are viviparous but deliver an altricial young after a short gestation supported by a fully functional placenta, so can shed light on the evolution and time of acquisition of genomic imprinting. All orthologues of eutherian imprinted genes examined have a conserved expression in the marsupial placenta regardless of their imprint status. Differentially methylated regions (DMRs) are the most common mechanism controlling genomic imprinting in eutherian mammals, but none were found in the marsupial imprinted orthologues of IGF2 receptor (IGF2R), INS or mesoderm-specific transcript (MEST). Instead, histone modification appears to be the mechanism used to silence these genes. At least three genes in marsupials have DMRs: H19, IGF2 and PEG10. PEG10 is particularly interesting as it is derived from a retrotransposon, providing the first direct evidence that retrotransposon insertion can drive the evolution of an imprinted region and of a DMR in mammals. The insertion occurred after the prototherian-therian mammal divergence, suggesting that there may have been strong selection for the retention of imprinted regions that arose during the evolution of placentation. There is currently no evidence for genomic imprinting in the egg-laying monotreme mammals. However, since these mammals do have a short-lived placenta, imprinting appears to be correlated with viviparity but not placentation.

Reproduction (2008) 136 523-531
\end{abstract}

\section{Introduction}

Genomic imprinting, the expression of a single allele from one, but not both chromosomes dependent on parent of origin, is a widespread epigenetic phenomenon in eutherian mammals, which is essential for the normal development of the eutherian placenta (Georgiades et al. 2001, Coan et al. 2005, Morison et al. 2005). In mammals, imprinting of a number of genes evolved about the same time that viviparity arose in the therian ancestor of the marsupials and eutherians, leading to the hypothesis that these events are associated. However, viviparity has evolved (often multiple times) in all vertebrate taxa except birds as well as in many invertebrates, and in all species it depends on the evolution of an efficient system of maternal-fetal exchange - usually via a placenta (Amoroso et al. 1979). Clearly, genomic imprinting is not essential for viviparity to evolve. While marsupial and eutherian mammals are viviparous, one group, the monotremes, lay eggs. Nevertheless, even in monotremes, the conceptus depends on the acquisition of nutrients across the fetal membranes for its early growth to the somite stages (Hill \& Martin 1895, Griffiths 1978, Hughes 1993, Renfree 1995, Hughes \& Hall 1998). Thus, all mammals depend on a functional placenta as the site of maternal-fetal exchange for at least some of their development. Of the three fetal membranes - the amnion, the allantois and the yolk sac-only the latter two form a placenta when the chorion fuses with either the yolk sac to form a choriovitelline placenta or with the allantois to form a chorioallantoic placenta. The definitive mammalian placenta is a highly variable structure that may either be invasive or make only a superficial attachment to the maternal endometrium, but in all cases is critical for the survival of the fetus. In marsupials, the functional placenta is a choriovitelline one, and in only a few species, notably the bandicoot, does the allantois make contact with the chorion (Tyndale-Biscoe \& Renfree 1987, Freyer et al. 2003, 2007; Fig. 1).

Marsupials have been separated from eutherian mammals for between 125 and 145 million years (Luo et al. 2003, Bininda-Emonds et al. 2007; Fig. 2) and since they have a fully functional (albeit short-lived) placenta (Renfree 1977, 1982, 1995, Freyer et al. 2003, 2007), they are ideal mammals in which to test the origin and control of genomic imprinting. The yolk sac placenta is a useful model to examine the relationship between imprinting and placentation in divergent mammalian species because the embryos of both groups of therian mammals rely on a yolk sac placenta at some 

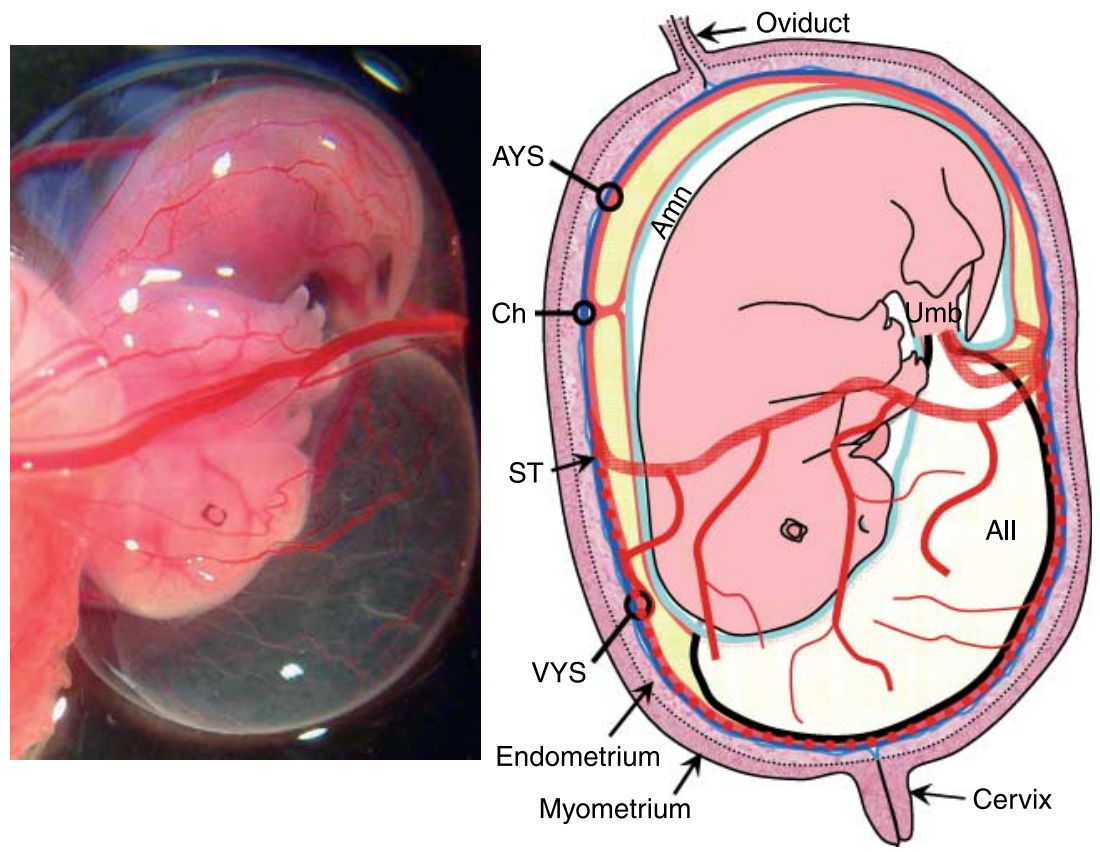

Figure 1 Day 25 tammar wallaby fetus in its fetal membranes. The amnion (Amn) completely surrounds the fetus. The large fluid-filled allantois (All) is completely enclosed within the yolk sac placenta. The vitelline vessels are limited by the sinus terminalis (ST) and enter the fetus via the umbilical cord (Umb). The vascular yolk sac (VYS) occupies about two-thirds of the total surface area of the placenta while the avascular (AYS) region remains bilaminar. The full-term fetus weighs around $400 \mathrm{mg}$ with a crown-rump length of 16-17 mm. Ch, chorion. stages of pregnancy (Mossman 1987, Tyndale-Biscoe \& Renfree 1987). All orthologues of eutherian imprinted genes so far examined have a conserved expression in the marsupial placenta regardless of their marsupial imprint status (Fig. 2).

Since imprinting results in monoallelic expression, it negates the advantage of diploidy, namely the masking of deleterious alleles. The advantages of imprinting must therefore outweigh its costs in increasing susceptibility to disease. Several hypotheses offer a rationale for the existence of genomic imprinting (Wilkins \& Haig 2003). However, the hypothesis that fits the observations most

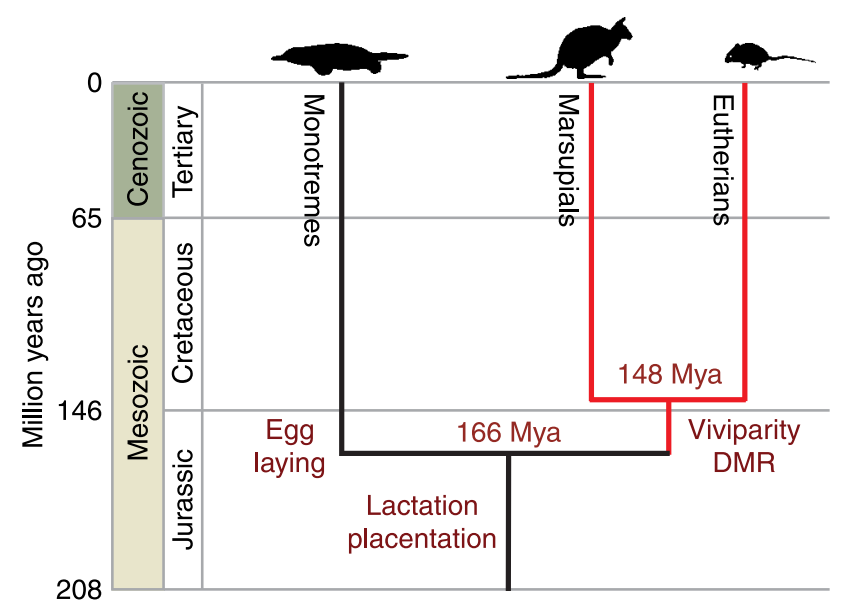

Figure 2 Evolutionary tree showing times and characters associated with the acquisition of imprinting in mammals. Red line indicates imprinting and black shows imprinted alleles not yet detected. closely is the parental conflict hypothesis, later adapted and referred to as the kinship hypothesis (Haig \& Graham 1991, Moore \& Haig 1991, Haig 1997, Wilkins \& Haig 2003). The parental conflict hypothesis proposes that imprinting is the product of the asymmetric selection on parental genomes for the development of a conceptus. Selection would favour the expression of paternal genes that increase the chance of survival of the offspring by increasing nutrient transfer at the expense of the mother. Conversely, selection would favour maternally inherited genes that increase maternal survival by restraining nutritional demands of the young on the mother. The supply and demand hypothesis (Reik et al. 2003), a further interpretation of the conflict hypothesis, suggests that the total effects of maternally and paternally expressed genes will determine the balance of fetal and maternal nutritional systems.

Many eutherian imprinted genes fit the predictions of the conflict hypothesis since a key site of imprinted expression is the placenta, which regulates the transfer of nutrients from mother and young, and is a key site of imprinted gene expression in eutherians (Guillemot et al. 1995, Georgiades et al. 2001, Constancia et al. 2002, Coan et al. 2006, Fowden et al. 2006). However, imprinted genes can also exert their effects in the early embryo, in placentation, parturition, and post partum, and imprint status can vary according to the developmental stage or tissue type. The extent of silencing of the imprinted allele can also differ between genes, tissues and species.

The different reproductive strategy of marsupials of a short gestation delivering an altricial young followed by a relatively long lactation compared with most 
eutherians makes them ideal models in which to examine the evolutionary origins of imprinting. Investigations of imprinted genes and their functions during marsupial placentation have provided great insight into the origins and role of genomic imprinting in mammals. In marsupials in which the placenta is relatively short lived and provides a small contribution to growth of the offspring, imprinting is predicted to be less rigorously selected, whereas in eutherians with a relatively greater investment in embryo growth conferred by the placenta, imprinting should be more strongly selected. Here, we review how investigations in marsupials have influenced our understanding of the selective forces driving the evolution of imprinting in mammals.

\section{Reproductive strategy and the stringency of placental imprinting}

To date, imprinting has been examined in only three species of marsupial; the Australian tammar wallaby and the American grey short-tailed and Virginia opossums (Killian et al. 2000, O'Neill et al. 2000, Suzuki et al. 2005; Table 1). Only in the tammar has genomic imprinting been identified in the marsupial placenta. However, the imprint status is incomplete in most of these genes. Rather than the robust silencing most often observed in eutherians, there is 'leaky' expression from the silent parental allele. In the placenta of the tammar, IGF2, PEG//mesoderm-specific transcript (MEST) and INS are incompletely imprinted, with preferential expression from the paternal allele, but with residual expression persisting from the maternal allele (Suzuki et al. 2005, Ager et al. 2007). In eutherians, incomplete imprinting can occur but is usually stage or tissue specific (Vu \& Hoffman 1994, Deltour et al. 1995,
Matsuoka et al. 1996, Watanabe \& Barlow 1996). The leaky expression seen in marsupial genes may be due to the absence of a differentially methylated region (DMR) in these alleles, which could be the result of many causes including the reduced selective pressure driving complete allele silencing in this mammalian lineage. Instead, it appears that histone modifications play a vital role in coordinating imprinted expression in marsupials. Such mechanisms are important for the control and maintenance of many imprinted genes including $\lg f 2 r$ (Vu et al. 2006), and Kcnq1 (Monk et al. 2006) in the mouse placenta. However, further investigations are required to determine the precise epigenetic modifications responsible for imprinting in marsupials at nonDMR-associated loci.

Despite leaky expression, imprinting may be just as important for successful reproduction in marsupials as in eutherians. There is huge disparity in the potential for sibling conflict in the three species of marsupial where we have data on imprinting. The tammar has a single young in an annual cycle that means each young has weaned before the mother breeds again, so there is little potential for direct sibling competition. However, the ancestral marsupials, like opossums, were most likely polytocous. Opossums have between 15 and 30 young per pregnancy, out of which only 10-14 successfully attach to a teat to begin sucking. This provides great potential for post-natal sibling competition. The first born and fastest to reach and attach to the teats will have a dramatic survival advantage over those more tardy. In addition, only $6-8$ out of the $10-14$ young that attach to the teat survive to weaning. IGF2 is incompletely imprinted in the tammar (Suzuki et al. 2005), but IGF2 imprinting in the opossum appears complete $\left(\mathrm{O}^{\prime}\right.$ Neill et al. 2000). However, the placenta was not examined in

Table 1 The imprint status of marsupial orthologues of eutherian imprinted genes in three species of marsupial (tammar, Macropus eugenii; Virginia opossum, Didelphis virginiana; and grey short-tailed opossum, Monodelphis domestica). In addition to the imprint status, the direction of expression and whether imprinting was complete are indicated. In two studies imprinting appeared incomplete. However, neither study used quantitative methods, and low expression from the silent allele may have gone undetected.

\begin{tabular}{|c|c|c|c|c|c|}
\hline Gene & Species & $\begin{array}{l}\text { Imprinted } \\
\text { (expression) }\end{array}$ & $\begin{array}{l}\text { Complete or } \\
\text { incomplete }\end{array}$ & $\begin{array}{l}\text { DMR } \\
\text { associated? }\end{array}$ & Reference \\
\hline CDKN1C & M. eugenii & No & Not applicable & & $\begin{array}{l}\text { Suzuki et al. (2005) and Ager } \\
\text { et al. (2008b) }\end{array}$ \\
\hline$D L K 1$ & $\begin{array}{l}\text { M. domestica, } \\
\text { M. eugenii }\end{array}$ & No & Not applicable & & $\begin{array}{l}\text { Weidman et al. (2006a, 2006b) } \\
\text { and Edwards et al. (2008) }\end{array}$ \\
\hline H19 & M. eugenii & Yes (paternal) & Appears complete & Yes & Smits et al. (2008) \\
\hline IGF2 & $\begin{array}{l}\text { M. eugenii and } \\
\text { M. domestica }\end{array}$ & Yes (paternal) & $\begin{array}{l}\text { Incomplete } \\
\text { Appears complete }\end{array}$ & Yes & $\begin{array}{l}\text { Suzuki et al. (2005), Ager et al. } \\
\text { (2008a) and Lawton etal. (2008) }\end{array}$ \\
\hline IGF2R & D. virginiana & Yes (maternal) & Appears complete & & Killian et al. (2000) \\
\hline INS & M. eugenii & Yes (paternal) & Incomplete & & Ager et al. (2007) \\
\hline MEG3 & M. domestica & Gene absent & Not applicable & & Weidman et al. (2006a, 2006b) \\
\hline NNAT & M. domestica & Gene absent & Not applicable & & Evans et al. (2005) \\
\hline PEG1/MEST & M. eugenii & Yes (paternal) & Incomplete & & Suzuki et al. (2005) \\
\hline PEG10 & M. eugenii & Yes (paternal) & Incomplete & Yes & Suzuki et al. (2007) \\
\hline SNRPN & M. eugenii & No & Not applicable & & Rapkins et al. (2006) \\
\hline UBE3A & M. eugenii & No & Not applicable & & Rapkins et al. (2006) \\
\hline DIO3 & M. eugenii & No & Not applicable & & Edwards et al. (2008) \\
\hline
\end{tabular}


that study, so there may be tissue-specific differences. Imprinted maternal expression of IGF2R likewise appears complete in the Virginia opossum (Killian et al. 2000). However, in both studies non-quantitative methods were used to examine gene expression, so weak leaky expression may have gone unnoticed. Further analysis of imprinting in the placental membranes of these species is needed to resolve this question.

\section{Complex regulatory mechanisms accumulate within imprinted regions}

Once established, genomic imprinting appears to spread to encompass neighbouring genes within the region and eventually leads to the complex reciprocal imprinted mechanisms occurring within a syntenic region.

The IGF2-H19 cluster is the best-studied imprinting domain in mammals. It is highly conserved in the marsupials and retains many, but not all, of the imprinting features of its eutherian counterpart. Recently, DMRs have been identified in both IFG2 and H19 in marsupials (Table 1). IGF2 is imprinted and DMR associated in the short-tailed opossum although the precise silencing control mechanisms differ from that of eutherians (Lawton et al. 2008). Similarly, H19, a noncoding RNA, is also imprinted and DMR associated in two marsupials, the tammar and short-tailed opossum (Smits et al. 2008). However, differences in regions of the H19 miRNA structure suggest that it may have different targets in marsupials and eutherian mammals. IGF2 is an essential gene for both the fetus and placenta in eutherian mammals. The precise function of this gene and the evolution of the IGF2 region were further investigated in marsupials to determine the evolutionary origins of imprinting in this well-characterised site. IGF2 mRNA and protein are present in the marsupial placenta together with its receptors (Ager et al. 2008a; Fig. 3). This suggests that IGF2 plays a conserved mitogenic role in the mammalian placenta. The mitogenic effects of IGF2 are thought to be antagonised by the action of the CDKN1C gene. CDKN1C and IGF2 are oppositely imprinted, antagonistic in function and syntenic in the mouse and human. However, in marsupials, while the genes remain in synteny, only IGF2 is imprinted. Despite this, CDKN1C protein was present in the tammar wallaby placenta suggesting its function in placental development preceded its acquisition of imprinting (Ager et al. 2008b). Therefore, CDKN1C imprinting is not contingent upon its synteny with IGF2 or its placental expression in mammals. In the mouse $C d k n 1 c$, imprinting is regulated by the antisense transcript Kcnq1ot1, derived from an intron of the $K c n q 1$ gene and regulated by an imprinting control region (ICR). Marsupials still produce an antisense $K C N Q 1 O T 1$ transcript, but there is no evidence of the ICR and it does not cause imprinting of the neighbouring CDKN1C gene (Ager et al. 2008b;
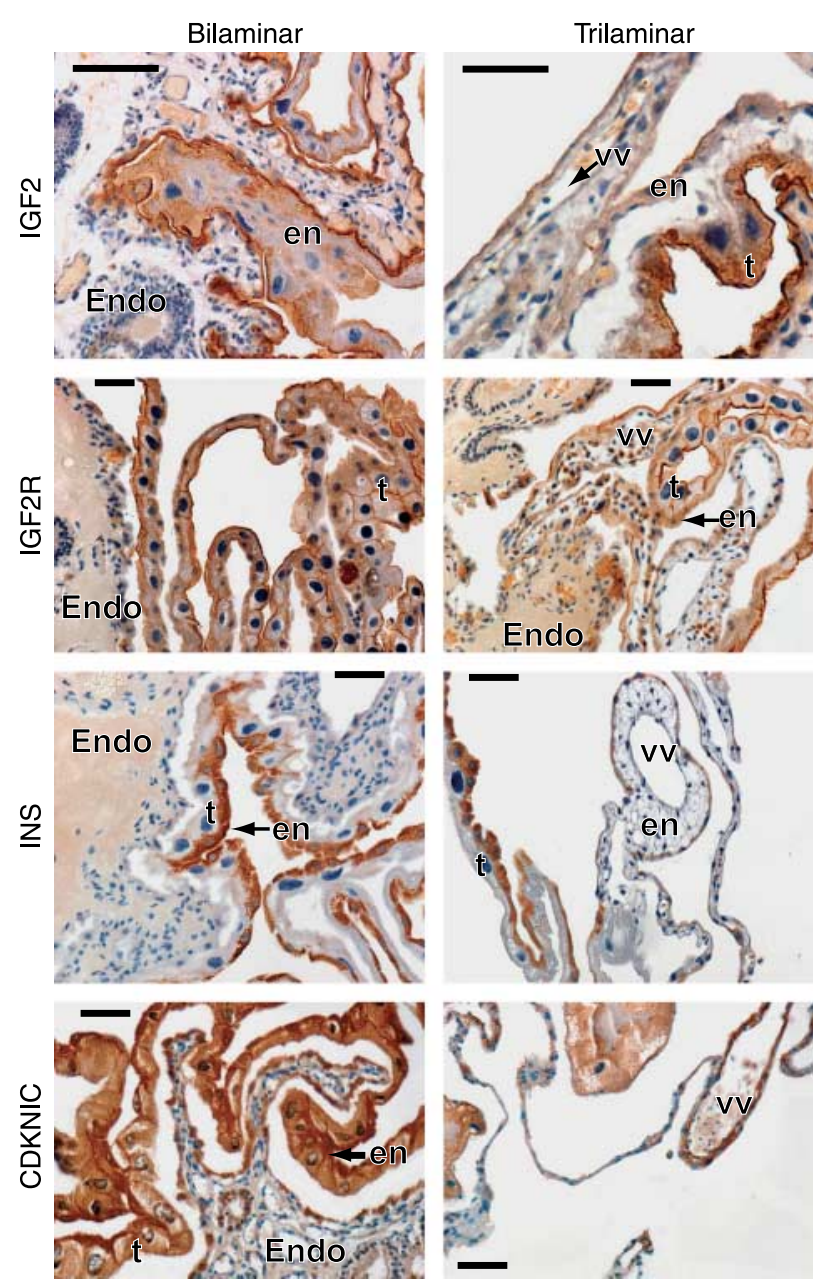

Figure 3 Protein distribution of imprinted genes in the marsupial placenta. Protein from three imprinted genes (IGF2, IFG2R and INS) and one non-imprinted (CDKN1C) gene are shown in brown; tissue is counterstained blue. All samples were examined in the placental samples were from late stage fetuses. Endo, endometrium; VV, vitelline vessel; te, trophoectoderm; en, endoderm. Data from Ager et al. (2007, 2008a, 2008b).

Fig. 4). A similar situation is seen in the IGF2R region of opossums (Didelphis virginiana and Monodelphis domestica) where there is no evidence of a DMR associated with IGF2R silencing. IGF2R is imprinted despite the absence of antisense expression of $A I R$ (Weidman et al. 2006a, 2006b). Antisense transcription within imprinted regions therefore does not appear to have any mechanistic relationship to the imprint status of the surrounding genes. In the IGF2 cluster, antisense transcription preceded the acquisition of imprinting, while in IGF2R it evolved after imprinting and may further stabilise silencing of the region in eutherians. Together, the relatively less complex regulation of gene transcription within this region in marsupials demonstrates the stepwise accumulation of control mechanisms within imprinted domains in eutherian mammals (Fig. 4). 

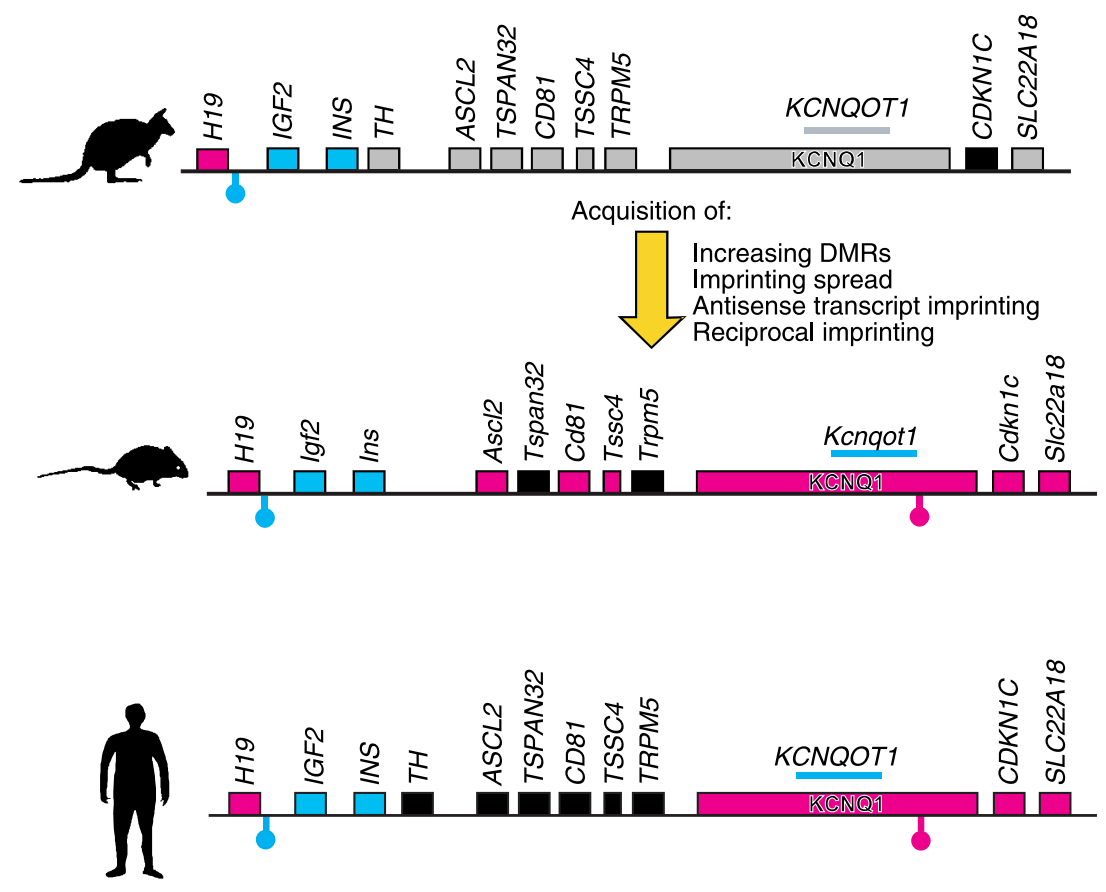

Figure 4 Evolution of the IGF2 domain. Despite the absence of imprinting, CDKN1C protein was present in the tammar wallaby placenta. Genomic analysis of the tammar region confirmed that CDKN1C is syntenic with IGF2. While the KCNQ1OT1 promoter elements could not be detected in intron 10 of KCNQ1, the antisense KCNQ1OT1 transcript, which regulates CDKN1C imprinting in human and mouse, is still expressed. CDKN1C synteny with IGF2 suggests that imprinting of the two genes did not occur concurrently to balance maternal and paternal influences on the growth of the placenta. The expression of KCNQ1OT1 in the absence of CDKN1C imprinting suggests that antisense transcription at this locus preceded imprinting of this domain. These findings demonstrate the stepwise accumulation of control mechanisms within imprinted domains and show that CDKN1C imprinting cannot be due to its synteny with IGF2 or with its placental expression in mammals. Blue indicates paternally expressed alleles, pink indicates maternally expressed alleles, black indicates non-imprinted genes and grey indicates those not yet investigated. Top panel shows the tammar wallaby locus, middle panel shows the mouse and bottom panel the human orthologous regions. Blue and pink lollypops indicate paternal and maternal DMRs respectively. Data from Ager et al. (2008b).

\section{Placental expression is sufficient to drive genomic imprinting}

The insulin gene (INS) was particularly interesting to examine in marsupials, as its imprinting in humans and mice is restricted to the yolk sac (Moore et al. 2001). The tammar wallaby orthologue is also expressed in the yolk sac placenta and shows genomic imprinting (Ager et al. 2007; Figs 3 and 4). This suggests not only that INS plays a critical role in the function of the mammalian placenta, but also that this role is sufficient to have driven monoallelic expression in this tissue. The placental expression of INS is consistent with it playing a critical role in the function of the mammalian placenta. However, the monoallelic expression in this tissue is surprising given the minimal maternal resources needed to grow the tiny, altricial marsupial neonate, which seems unlikely to provide a 'conflict' for resources between the mother and the fetus. Furthermore, the restricted imprinting of INS suggests that imprinting evolved in the placenta, independently of other tissues, in the therian ancestor of marsupials and eutherians. This finding is of significance as it supports suggestion that there was coevolution of genomic imprinting with placental development in mammals (Kaneko-Ishino et al. 2003, 2006).

\section{The formation of a new imprinted cluster}

Analysis of several imprinted clusters between marsupials and eutherians has shown the importance of retrotransposons in triggering the evolution of imprinting. Genomic imprinting, at least methylation-based imprinting, may have evolved from molecular mechanisms used to silence retrotransposons: the host defence hypothesis (Barlow 1993, McDonald et al. 2005, Youngson et al. 2005). Therefore, retrotransposons that have evolved a function in the placenta, such as PEG10 (Ono et al. 2006), may be more frequently associated with silencing conferred by differential methylation in both marsupials and eutherians. The host defence hypothesis suggests that silencing of foreign DNA by methylation fortuitously provided a mechanism to regulate parental-specific gene expression (Barlow 1993). Comparative analysis of the PEG10 region across mammals has shown that it is a recent addition to the 
mammalian genome and was derived from an insertion of a copy of the Sushi-ichi transposon. This occurred in the therian genome before the marsupial-eutherian split (Suzuki et al. 2007; Fig. 5). Peg10 is also imprinted in both marsupials and eutherians, suggesting that its acquisition of imprinting evolved with its insertion into the genome. Furthermore, PEG10 was also the first marsupial imprinted gene shown to be associated with a DMR. This is in direct support of the host defence hypothesis to explain the origin of (at least methylationassociated) imprinting, and indicates that DMR-associated imprinting evolved before the marsupial eutherian split. While in marsupials it is just PEG10 gene that is imprinted, in eutherians the imprinting of this region has spread to encompass neighbouring genes (Fig. 5). In this way, the insertion of a retrotransposon can trigger the evolution of an entire imprinted region.

A similar mechanism appears to have sparked imprinting in the Prader-Willi/Angelman syndrome region in mice and humans. Again, comparative mapping of this region in marsupials and eutherians has shown that this region has only recently evolved in the eutherian mammals, after the fusion of the marsupial biallelic $U B E 3 A$ region with the biallelic $S N R P N$ region, derived by a duplication of the SNRPB gene (Rapkins et al. 2006). Concomitant with this was the insertion of retroposed genes and small nucleolar RNAs that were the potential driving force behind the acquisition if imprinting to the region, again derived from host defence mechanisms.

Another region in which imprinting appears to be derived from retrotansposon insertion is the DLK/DIO3 region (Edwards et al. 2008). In marsupials both DLK and DIO3 are biallelically expressed, but in eutherians both genes are imprinted. The acquisition of imprinting in the eutherian domain is concomitant with the appearance of non-coding transcripts including microRNAs and C/D snoRNAs in the region and is derived from a recent retrotransposition event only in the eutherian domain.

Each of these cases lends strong support to the host defence hypothesis and strongly implies that retrotransposition is a key driving force behind the evolution of mammalian genomic imprinting.

\section{Future studies: influences of imprinting in the post partum period}

Parental conflict also arises in areas of postpartum maternal and offspring behaviour (Keverne et al. 1996, Haig 1997, 2000, Keverne 2001, Haig \& Wharton 2003, Keverne \& Curley 2008). Mothers carrying mutations in imprinted genes, such as PEG3, have impaired maternal behaviour including a failure to retrieve pups, suckle them and ingest the placenta (Keverne 2001). Other imprinted genes regulate post-natal behaviour of the young and when disrupted, such as in Prader-Willi and Angelman syndromes, can result in hyper- or hypoactivity, mental retardation and an inability to regulate appetite. Adult female mice carrying a paternal knockout of Peg3 have impaired maternal care and lactation is disrupted ( $\mathrm{Li}$ et al. 1999, Murphy et al. 2001). A reduction in oxytocin-positive neurons in mutant Peg3 females results in abnormal hypothalamic function, which controls milk ejection (Li et al. 1999). IGF2 may mediate prolactin-induced growth of the mammary gland (Hovey et al. 2003). For some imprinted genes, disruption of their imprint status is associated with breast cancer development and these genes, such as

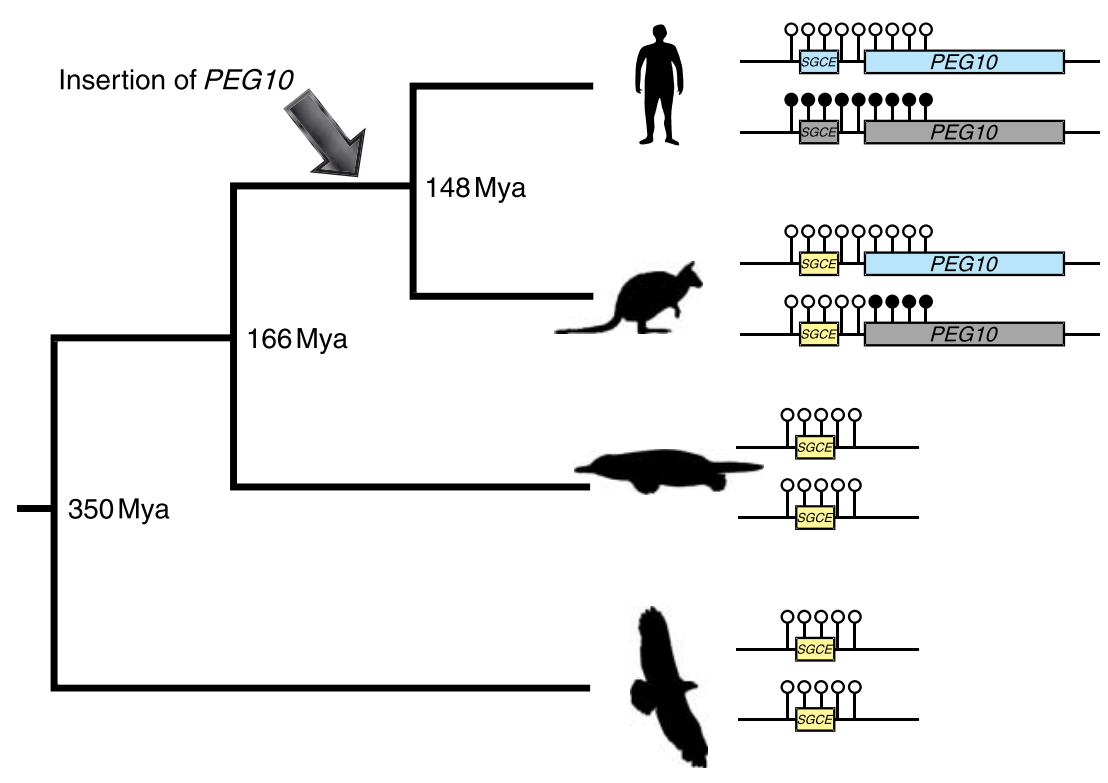

Figure 5 Evolution of the PEG10 region. PEG10 was inserted into the therian genome at least 130 million years ago (arrow). This was concomitant with the formation of a DMR, silencing the maternally inherited PEG10 gene copy. In eutherian mammals (top branch of the tree), differential methylation has spread encompass the SGCE gene as well. In the marsupial lineage (second from top branch of tree), differential methylation is only found associated with PEG10. In the monotremes and birds (bottom two branches of tree), there is no PEG10 gene and SGCE does not appear to be differentially methylated. The black lollipops indicate DNA methylation of $\mathrm{CpG}$ sites and the grey boxes represent silenced alleles. Redrawn from Suzuki et al. (2007). 

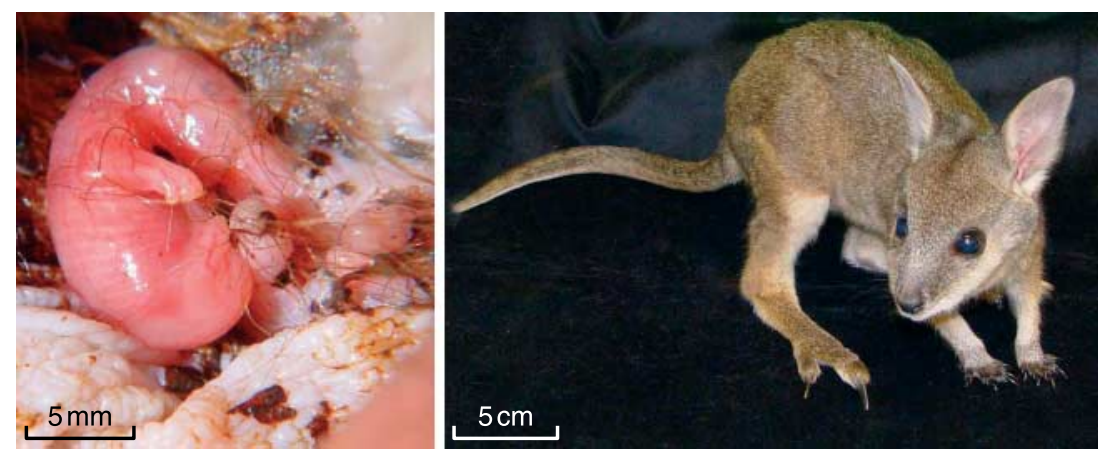

Figure 6 Neonate on teat (left) and day 180 pouch young (right) of the tammar wallaby. A typical tammar mother weighs $5 \mathrm{~kg}$, so the total investment in the $400 \mathrm{mg}$ neonate is relatively small. By day 180, the young is starting to wean, but the young is not fully weaned until after day 280 when the young weighs around $2 \mathrm{~kg}$.

PEG1/MEST (Pedersen et al. 1999), are imprinted in fetal tissues of the tammar (Suzuki et al. 2005) as well as in other mammals.

Marsupials deliver highly altricial young, but these young then spend a relatively long time, usually within a pouch (Renfree 2006), dependent on the mother for milk (Fig. 6). In the tammar, while gestation is only 26.5 days (Renfree et al. 1989) lactation is about 9 months long (Tyndale-Biscoe \& Renfree 1987). Much of the organ growth and development occurs during this period, supported by milk that is of changing composition, tailormade for each stage of the development of the young (Tyndale-Biscoe \& Janssens 1988). It would be interesting to examine the expression of imprinted genes in postnatal stages in marsupial mothers and young.

\section{Conclusions: what have marsupials taught us about genomic imprinting?}

By comparing genomic imprinting in groups of mammals with different reproductive strategies and placental contributions to fetal development, we can define some of the selective pressures that may have led to the evolution of genomic imprinting. Marsupials have retained imprinted gene expression in their placenta, clearly indicating the evolutionary origin of this phenomenon in the viviparous therian ancestor with viviparity. It also suggests that despite the relatively small demand on placental nutrition, the marsupial placenta is subject to sufficient evolutionary pressure to retain genomic imprinting. However, overall the imprinted regions of marsupials so far appear less complex and contain fewer imprinted alleles than their eutherian orthologues. In addition, imprinting of most loci is more relaxed in marsupials with individual loci showing biased expression based on parent of origin as opposed to complete allele-specific silencing as often seen in eutherian species. While marsupials do have the ability to regulate genes by DMRs and confer complete genetic silencing, this mechanism has apparently not been widely co-opted to regulate many imprinted genes. Taken together, this suggests that there was greater evolutionary pressure for the evolution of imprinting mechanisms in the eutherian compared with the marsupial lineage, as reflected by their overall relative contributions of the placenta to offspring growth. Nevertheless, it must be emphasised that only three species and 12 genes have been analysed in a relatively few tissues in marsupials so far. Placental expression has been examined in only one species, the tammar. These are early days in terms of understanding the importance of imprinting in this group that represent only $6 \%$ (Kirsch 1977) of living mammals.

To date, all studies of imprinted loci in marsupials have been informed from imprinted orthologues in eutherian mammals. However, given the difference in their reproductive strategies, if the conflict hypothesis holds true, it is likely that new genes would have acquired imprinting in the marsupial lineage. Imprinting is more likely to be associated with post-natal nutrient provisioning, which is greatly extended in marsupials due to their lengthy and sophisticated lactation and the maternal behaviour associated with having a young in a pouch. Further work will lead to some exciting discoveries about the role of genes that have acquired imprinting in the marsupial lineage.

\section{Declaration of interest}

The authors declare that there is no conflict of interest that could be perceived as prejudicing the impartiality of the research reported.

\section{Funding}

Our research was supported by the ARC Centre of Excellence in Kangaroo Genomics; A J P was supported by an NHMRC RD Wright Fellowship and $M B R$ by an ARC Federation Fellowship.

\section{Acknowledgements}

We thank our colleagues in Japan (Profs Fumi Ishino and Tomo Kaneko-Ishino, Dr Shunsuke Suzuki and staff) and in Cambridge (Drs Anne Ferguson-Smith, Carol Edwards, Wolf Reik, Guillaume Smits, and Gavin Kelsey) for ongoing collaborations on imprinting in the marsupial placenta. 


\section{References}

Ager El, Suzuki S, Pask AJ, Shaw G, Ishino F \& Renfree MB 2007 Insulin is imprinted in the placenta of the marsupial, Macropus eugenii. Developmental Biology 309 317-328.

Ager El, Pask AJ, Shaw G \& Renfree MB 2008a Expression and protein localisation of IGF2 in the marsupial placenta. BMC Developmental Biology 817.

Ager El, Pask AJ, Gehring HM, Shaw G \& Renfree MB $2008 b$ Evolution of the CDKN1C/KCNQOT1 imprinted domain. BMC Evolutionary Biology 8163.

Amoroso EC, Heap RB \& Renfree MB 1979 Hormones and the evolution of viviparity. In Hormones and Evolution, pp 925-989. Ed. EJW Barrington. New York: Academic Press.

Barlow DP 1993 Methylation and imprinting: from host defense to gene regulation? Science 260 309-310.

Bininda-Emonds OR, Cardillo $M$, Jones KE, MacPhee RD, Beck RM, Grenyer R, Price SA, Vos RA, Gittleman JL \& Purvis A 2007 The delayed rise of present-day mammals. Nature 446 507-512.

Coan PM, Burton GJ \& Ferguson-Smith AC 2005 Imprinted genes in the placenta - a review. Placenta 26 S10-S20.

Coan PM, Conroy N, Burton GJ \& Ferguson-Smith AC 2006 Origin and characteristics of glycogen cells in the developing murine placenta. Developmental Dynamics 235 3280-3294.

Constância $M$, Hemberger $M$, Hughes J, Dean W, Ferguson-Smith A, Fundele R, Stewart F, Kelsey G, Fowden A, Sibley C et al. 2002 Placentalspecific IGF-II is a major modulator of placental and fetal growth. Nature 417 945-948.

Deltour L, Montagutelli X, Guenet JL, Jami J \& Paldi A 1995 Tissue- and developmental stage-specific imprinting of the mouse proinsulin gene, Ins2. Developmental Biology 168 686-688.

Edwards CA, Mungall AJ, Matthews L, Ryder E, Gray DJ, Pask AJ, Shaw G, Graves JAM, Rogers J, the SAVOIR Consortium et al. 2008 The evolution of an imprinted domain in mammals. PLoS Biology 6 e135.

Evans HK, Weidman JR, Cowley DO \& Jirtle RL 2005 Comparative phylogenetic analysis of blcap/nnat reveals eutherian-specific imprinted gene. Molecular Biology and Evolution 22 1740-1748.

Fowden AL, Sibley C, Reik W \& Constancia M 2006 Imprinted genes, placental development and fetal growth. Hormone Research 65 (Supplement 3) 50-58.

Freyer C, Zeller U \& Renfree MB 2003 The marsupial placenta: a phylogenetic analysis. Journal of Experimental Zoology 299 59-77.

Freyer C, Zeller U \& Renfree MB 2007 Placental function in two distantly related marsupials. Placenta 28 249-257.

Georgiades P, Watkins M, Burton GJ \& Ferguson-Smith AC 2001 Roles for genomic imprinting and the zygotic genome in placental development. PNAS 98 4522-4527.

Griffiths ME 1978 The Biology of the Monotremes. New York: Academic Press.

Guillemot F, Caspary T, Tilghman SM, Copeland NG, Gilbert DJ, Jenkins NA, Anderson DJ, Joyner AL, Rossant J \& Nagy A 1995 Genomic imprinting of Mash2, a mouse gene required for trophoblast development. Nature Genetics 9 235-242.

Haig D 1997 Parental antagonism, relatedness asymmetries, and genomic imprinting. Proceedings. Biological Sciences 264 1657-1662.

Haig D 2000 Genomic imprinting, sex-biased dispersal, and social behaviour. Annals of the New York Academy of Sciences 907 149-163.

Haig D \& Graham C 1991 Genomic imprinting and the strange case of the insulin-like growth factor II receptor. Cell 64 1045-1046.

Haig D \& Wharton R 2003 Prader-Willi syndrome and the evolution of human childhood. American Journal of Human Biology 15 320-329.

Hill JP \& Martin CJ 1895 On a platypus embryo from the intra-uterine egg. Proceedings of the Linnean Society of New South Wales 10 43-74.

Hovey RC, Harris J, Hadsell DL, Lee AV, Ormandy CJ \& Vonderhaar BK 2003 Local insulin-like growth factor-II mediates prolactin-induced mammary gland development. Molecular Endocrinology 17 460-471.

Hughes RL 1993 Monotreme development with particular reference to the extraembryonic membranes. Journal of Experimental Zoology $\mathbf{2 6 6}$ 480-494.

Hughes RL \& Hall LS 1998 Early development and embryology of the platypus. Philosophical Transactions of the Royal Society of London. Series B 353 1101-1114.
Kaneko-Ishino T, Kohda T \& Ishino F 2003 The regulation and biological significance of genomic imprinting in mammals. Journal of Biochemistry 133 699-711.

Kaneko-Ishino T, Kohda T, Ono R \& Ishino F 2006 Complementation hypothesis: the necessity of a monoallelic gene expression mechanism in mammalian development. Cytogenetic and Genome Research 113 24-30.

Keverne EB 2001 Genomic imprinting, maternal care, and brain evolution. Hormones and Behavior 40 146-155.

Keverne EB \& Curley JP 2008 Epigenetics, brain evolution and behaviour. Frontiers in Neuroendocrinology 29 398-412.

Keverne EB, Fundele R, Narasimha M, Barton SC \& Surani MA 1996 Genomic imprinting and the differential roles of parental genomes in brain development. Brain Research. Developmental Brain Research 92 91-100.

Killian JK, Byrd JC, Jirtle JV, Munday BL, Stoskopf MK, MacDonald RG \& Jirtle RL 2000 M6P/IGF2R imprinting evolution in mammals. Molecular Cell 5 707-716.

Kirsch JAW 1977 The six-percent solution: second thoughts on the adaptedness of the marsupialia. American Scientist 65 276-288.

Lawton BR, Carone BR, Obergfell CJ, Ferreri GC, Gondolphi CM, Vandeberg JL, Imumorin I, O'Neill RJ \& $\mathbf{O}^{\prime}$ Neill MJ 2008 Genomic imprinting of IGF2 in marsupials is methylation dependent. BMC Genomics 9205.

Li L, Keverne EB, Aparicio SA, Ishino F, Barton SC \& Surani MA 1999 Regulation of maternal behavior and offspring growth by paternally expressed Peg3. Science 284 330-333.

Luo ZX, Ji Q, Wible JR \& Yuan CX 2003 An early cretaceous tribosphenic mammal and metatherian evolution. Science 302 1934-1940.

Matsuoka S, Thompson JS, Edwards MC, Bartletta JM, Grundy P, Kalikin LM, Harper JW, Elledge SJ \& Feinberg AP 1996 Imprinting of the gene encoding a human cyclin-dependent kinase inhibitor, p57KIP2, on chromosome 11p15. PNAS 93 3026-3030.

McDonald JF, Matzke MA \& Matzke AJ 2005 Host defenses to transposable elements and the evolution of genomic imprinting. Cytogenetic and Genome Research 110 242-249.

Monk D, Arnaud P, Apostolidou S, Hills FA, Kelsey G, Stanier P, Feil R \& Moore GE 2006 Limited evolutionary conservation of imprinting in the human placenta. PNAS 103 6623-6628.

Moore T \& Haig D 1991 Genomic imprinting in mammalian development: a parental tug-of-war. Trends in Genetics 7 45-49.

Moore GE, Abu-Amero SN, Bell G, Wakeling EL, Kingsnorth A, Stanier P, Jauniaux E \& Bennett ST 2001 Evidence that insulin is imprinted in the human yolk sac. Diabetes 50 199-203.

Morison IM, Ramsay JP \& Spencer HG 2005 A census of mammalian imprinting. Trends in Genetics 21 457-465.

Mossman H 1987 Vertebrate Fetal Membranes: Comparative Ontogeny and Morphology, Evolution, Phylogenetic Significance, Basic Functions, Research Opportunities. New Brunswick, NJ: Rutgers University Press.

Murphy SK, Wylie AA \& Jirtle RL 2001 Imprinting of PEG3, the human homologue of a mouse gene involved in nurturing behavior. Genomics 71 110-117.

O'Neill MJ, Ingram RS, Vrana PB \& Tilghman SM 2000 Allelic expression of IGF2 in marsupials and birds. Development Genes and Evolution 210 18-20.

Ono R, Nakamura K, Inoue K, Naruse M, Usami T, Wakisaka-Saito N, Hino T, Suzuki-Migishima R, Ogonuki N, Miki H et al. 2006 Deletion of Peg10, an imprinted gene acquired from a retrotransposon, causes early embryonic lethality. Nature Genetics 38 101-106.

Pedersen IS, Dervan PA, Broderick D, Harrison M, Miller N, Delany E, O'Shea D, Costello P, McGoldrick A, Keating G et al. 1999 Frequent loss of imprinting of PEG1/MEST in invasive breast cancer. Cancer Research 59 5449-5451.

Rapkins RW, Hore T, Smithwick M, Ager E, Pask AJ, Renfree MB, Kohn M, Hameister H, Nicholls RD, Deakin JE et al. 2006 Recent assembly of an imprinted domain from non-imprinted components. PLoS Genetics 2 1666-1675.

Reik W, Constância M, Fowden A, Anderson N, Dean W, FergusonSmith A, Tycko B \& Sibley C 2003 Regulation of supply and demand for maternal nutrients in mammals by imprinted genes. Journal of Physiology 547 35-44. 
Renfree MB 1977 Feto-placental influences in marsupial gestation. In Reproduction and Evolution, pp 325-331. Eds JH Calaby \& CH TyndaleBiscoe. Canberra: Australian Academy of Science.

Renfree MB 1982 Implantation and placentation. In Reproduction in Mammals, Second Edition. Book 2 Embryonic and Fetal Development, pp 26-69. Eds CR Austin \& RV Short. Cambridge: Cambridge University Press.

Renfree MB 1995 Monotreme and marsupial reproduction. Reproduction, Fertility, and Development 7 1003-1020.

Renfree MB 2006 Life in the pouch: womb with a view. Reproduction, Fertility, and Development 18 721-734.

Renfree MB, Fletcher TP, Blanden DR, Lewis PR, Shaw G, Gordon K, Short RV, Parer-Cook E \& Parer D 1989 Physiological and behavioural events around the time of birth in macropodid marsupials. In Kangaroos, Wallabies and Rat Kangaroos, pp 323-337. Eds G Grigg, P Jarman \& ID Hume. Sydney: Surrey Beatty \& Sons Pty. Ltd.

Smits G, Mungall AJ, Griffiths-Jones S, Smith P, Beury D, Matthews L, Rogers J, Pask AJ, Shaw G, Vandeberg JL et al. 2008 Conservation of the H19 noncoding RNA and H19-IGF2 imprinting mechanism in therians Nature Genetics 40 971-976.

Suzuki S, Renfree MB, Pask AJ, Shaw G, Kobayashi S, Kohada T, KanekoIshino T \& Ishino F 2005 Genomic imprinting of IGF2, P57 KIP2 and PEG1/MEST in a marsupial, the tammar wallaby. Mechanisms of Development 122 213-222.

Suzuki S, Ono R, Narita T, Pask AJ, Shaw G, Wang C, Kohda T, Alsop AE, Marshall Graves JA, Kohara Y et al. 2007 Retrotransposon silencing by DNA methylation can drive mammalian genomic imprinting. PLoS Genetics 3 0531-0537.

Tyndale-Biscoe CH \& Janssens PA (Eds) 1988 Development of Young Marsupials: Models for Biomedical Research. Berlin: Springer-Verlag.
Tyndale-Biscoe CH \& Renfree MB 1987 Reproductive Physiology of Marsupials, p 476. Cambridge: Cambridge University Press.

Vu TH \& Hoffman AR 1994 Promoter-specific imprinting of the human insulin-like growth factor-II gene. Nature 371 714-717.

Vu TH, Jirtle RL \& Hoffman AR 2006 Cross-species clues of an epigenetic imprinting regulatory code for the IGF2R gene. Cytogenetic and Genome Research 113 202-208.

Watanabe D \& Barlow DP 1996 Random and imprinted monoallelic expression. Genes to Cells $\mathbf{1}$ 795-802.

Weidman JR, Maloney KA \& Jirtle RL 2006a Comparative phylogenetic analysis reveals multiple non-imprinted isoforms of opossum Dlk1. Mammalian Genome 17 157-167.

Weidman JR, Dolinoy DC, Maloney KA, Cheng JF \& Jirtle RL $2006 b$ Imprinting of opossum Igf2r in the absence of differential methylation and air. Epigenetics $149-54$.

Wilkins JF \& Haig D 2003 What good is genomic imprinting: the function of parent-specific gene expression. Nature Reviews. Genetics 4 359-368.

Youngson NA, Kocialkowski S, Peel N \& Ferguson-Smith AC 2005 A small family of sushi-class retrotransposon-derived genes in mammals and their relation to genomic imprinting. Journal of Molecular Evolution 61 481-490.

Received 12 June 2008

First decision 8 July 2008

Revised manuscript received 10 September 2008

Accepted 18 September 2008 